\title{
Ligand-Based Electronic Effects on the Electrocatalytic Hydrogen Production by Thiosemicarbazone Nickel Complexes
}

Received 00th January 20xx, Accepted 00th January 20xx DOI: $10.1039 / \times 0 \times x 00000 x$

\begin{abstract}
Michael Papadakis, ${ }^{\text {a,b }}$ Alexandre Barrozo, ${ }^{a}$ Tatiana Straistari, ${ }^{\text {a }}$ Nicolas Queyriaux, ${ }^{c}$ Anisa Putri, ${ }^{a}$ Jennifer Fize, ${ }^{d}$ Michel Giorgi, ${ }^{\mathrm{e}}$ Marius Réglier, ${ }^{a}$ Julien Massin, ${ }^{a}$ Renaud Hardré, ${ }^{a}$ and Maylis Orio $*^{a}$

This work reports on the synthesis and characterization of a series of mononuclear thiosemicarbazone nickel complexes that display significant catalytic activity for hydrogen production in DMF using trifluoroacetic acid as the proton source. The ligand framework was chemically modified by varying the electron-donating abilities of the para substituents on the phenyl rings, which was expected to impact the capability of the resulting complexes to reduce protons into hydrogen. Over the four nickel complexes that were obtained, the one with the thiomethyl subsituent, $\mathbf{N i S C H}_{3}, \mathbf{w a s}$ found to overtake the catalytic performances of the parent complex $\mathbf{N i O C H}_{3}$ featuring lower overpotential values and similar maximum turnover frequencies. These results confirm the electronic effects of the ligand on HER when using thiosemicarbazone nickel complexes and support that chemical modifications can tune the catalytic performances of such systems.
\end{abstract}

\section{Introduction}

Along with economic growth, the demand and use of fuel has increased. The risk of depletion of fossil resources combined with environmental problems also reflects the unsustainability of the current energy model. ${ }^{1}$ The development of renewable energy sources that are environmentally friendly and affordable is of critical importance facing the $21^{\text {st }}$ century energy challenge. ${ }^{1}$ Hydrogen is regarded as a promising molecular fuel to address such a problem. ${ }^{2,3}$ Up to now, platinum-based catalysts possess the best performances among catalysts able to reduce protons to hydrogen. ${ }^{2}$ However, due to the scarcity and cost of this noble element, intense research has been performed to find alternative nonnoble transition metal catalysts. ${ }^{4}$ Nature can serve as a guide for such quest, as it offers efficient $\mathrm{H}_{2}$ evolution catalysts in the form of hydrogenases, organometallic enzymes containing nickel and/or iron sites whose catalytic performances rival commonly used platinum catalysts for hydrogen production. ${ }^{5,6}$ Hydrogenases thus offer fascinating blueprints for the design of new molecular catalysts based on Earth-abundant metals, and several studies indeed report homo-- ${ }^{7-9}$ and hetero-

\footnotetext{
Aix Marseille Univ, CNRS, Centrale Marseille, iSm2, Marseille, France.

E-mail:maylis.orio@univ-amu.fr

bniv. of Crete, Department of Chemistry, Laboratory of Bioinorganic chemistry, Voutes campus, Heraklion, Crete.

CNRS, LCC (Laboratoire de Chimie de Coordination), 31077 Toulouse, France

d. Univ. Grenoble Alpes, CNRS, CEA, IRIG, Laboratoire de Chimie et Biologie des Métaux, 17 rue des Martyrs, 38000 Grenoble, France.

e. Aix Marseille Univ, CNRS, Spectropole FR1739, Marseille, France.
}

binuclear ${ }^{10-12}$ metal complexes as electrocatalysts for hydrogen evolution reactivity (HER) reproducing the structure of the active site of hydrogenase. Besides these biomimetic approaches, a large number of molecular electrocatalysts have been developed in recent years. They involve mainly the conversion of chemical into electrical energy through the electrochemical oxidation of hydrogen using a metal. Particularly, such molecular electrocatalysts are the subject of a proper chemical design for the efficient hydrogen production at low overpotential. ${ }^{13-19}$ In this context, diverse ligand skeletons with cobalt and nickel-based complexes were found to generate molecular hydrogen in organic and aqueous media. ${ }^{20}$ Metal complexes based on thiosemicarbazone ligands are emerging as a new class of electrocatalyst for HER. ${ }^{21-26}$ Indeed, it was suggested that the introduction of proton relays in the second coordination sphere of the metal center combined with the use of redox-active ligands can be exploited to enhance or promote catalytic activity. ${ }^{27-29}$ These complexes thus present some interesting features relevant to electrocatalytic proton reduction: the thiosemicarbazone ligand has already been shown to be redox active while the presence of $\mathrm{S}$-donors and several $\mathrm{N}$-atoms allows for protonation of the ligand and can serve as proton relays. The ability to store electrons in the ligand rather than in the metal renders a variety of mechanisms for HER. Those will give freedom to design electrocatalysts in terms of flexibility and thermodynamics (reduction potentials and $\mathrm{pK}_{\mathrm{a}}$ values). ${ }^{30}$ In 2016, our group reported the synthesis and characterization of a mononuclear nickel complex, $\mathrm{NiOCH}_{3}$, an efficient electrocatalyst for HER. ${ }^{24}$ The use of catalytic Tafel plot $^{31}$ to 
benchmark its catalytic performances with other catalysts reported in the literature demonstrated that this complex is among the best catalysts reported so far with respect to overpotential requirement. A ligand-assisted metal-centered reactivity was proposed for this system with a two-step mechanism involving initial ligand-centered reduction and protonation followed by metal-centered reduction leading to the formation of a stable hydride intermediate. ${ }^{24,32-34}$

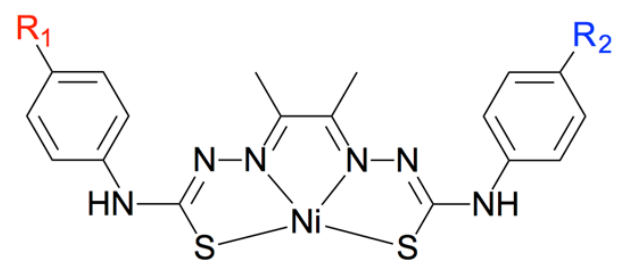

Fig.1 Thiosemicarbazone nickel complexes under investigation with $R_{1}, R_{2}=$ $\mathrm{OCH}_{3}, \mathrm{SCH}_{3}, \mathrm{~N}\left(\mathrm{CH}_{3}\right)_{2}$ or $\mathrm{CN}$

Following this work, our goal is now to improve the catalytic performances for hydrogen production of the nickel complex bearing methoxy substituents $\left(\mathrm{R}_{1}=\mathrm{R}_{2}=\mathrm{OCH}_{3}\right)$. For that purpose, we have prepared and characterized a series of mononuclear complexes by varying the chemical nature of the $R_{1}$ and $R_{2}$ phenyl ring substituents (Figure 1). Based on Hammett $\sigma$ Constants, we modified our parent thiosemicarbazone ligand $\mathbf{H}_{\mathbf{2}} \mathbf{L}$ by tuning the electron withdrawing/donating character of both substituents. Our study also included the synthesis of an asymmetric ligand that combines at the same time the electron withdrawing or donating abilities of two different $R_{1}$ and $R_{2}$ groups. The resulting complexes display a wide range of electron-donating abilities of their para substituents. Their capability to mediate hydrogen evolution was evaluated to determine the impact of the electronic substitution on the two parameters that are key for catalyst evaluation: the overvoltage and the rate of catalysis.

\section{Results and Discussion}

\section{Synthesis and Characterization}

In this work, two types of new ligands were considered: (i) symmetric ligands built with three different substituents including thiomethyl $\left(\mathrm{SCH}_{3}\right)$; dimethylamino $\left(\mathrm{N}\left(\mathrm{CH}_{3}\right)_{2}\right)$ and cyano $(\mathrm{CN})$ groups and (ii) an asymetric ligand which combines dimethylamino and cyano $\left(\mathrm{N}\left(\mathrm{CH}_{3}\right)_{2}, \mathrm{CN}\right)$ substituents mixing the two opposite strongest mesomeric effects in a molecule and therefore presenting an electronic "push-pull effect".

These ligands were designed such that their properties were a function of the substituents at the para position of the phenyl ring. Indeed, the Hammett constants of the chosen substituents combine mesomeric and inductive effects induced by para-substitutions. The mesomeric effect, which is a property of functional groups used in a qualitative way, describes the electron withdrawing or donating properties of substituents based on relevant resonance structure, ${ }^{35}$ while the inductive effect is an experimentally observed effect of the transmission of charge through a chain of atoms in a molecule, resulting in a permanent dipole in a bond. ${ }^{36}$

The protonated ligands, referred here as $\mathbf{H}_{\mathbf{2}} \mathbf{L}$, were synthesized by the reaction of 2,3-dihydrazide-butane with two equivalents of isothiocyanate derivative in ethanol heated at reflux as previously reported for the parent ligand with methoxy substituents. ${ }^{24}$ The products were obtained as yellow solids in good yields (> 56\%) and were further used to generate the metal complexes. The NiL complexes were obtained in good yield ( $>80 \%$ ) by adding one equivalent of nickel nitrate to a suspension of $\mathbf{H}_{\mathbf{2}} \mathbf{L}$ ligands in methanol. The crude compounds precipitated as solid powders after washing with methanol and did not require any further purification (Scheme 1). The sets of ligands and complexes were fully characterized by HRMS ESI, IR and NMR spectroscopy (see Supporting Information).

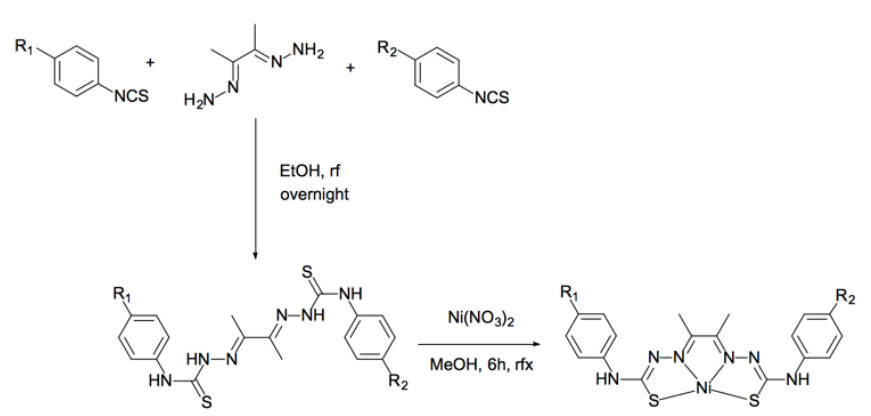

Scheme 1 Synthetic route for both the ligands $\mathbf{H}_{2} \mathbf{L}$ and the metal complexes NiL.

Our attempts to obtain suitable crystals for X-ray diffraction analysis of the $\mathbf{N i L}$ complexes remained unsuccessful. As the PdL complex with $\mathrm{OCH}_{3}$ substituent was previously reported to be isostructural with the nickel analogue ${ }^{37}$ the palladium was also used for a comparative analysis of the structural features of NiL. The PdL complexes were prepared in refluxing acetonitrile by interaction of one equivalent of $\mathrm{H}_{2} \mathrm{~L}$ ligands in DMF with one equivalent of palladium chloride. A series of four PdL complexes was obtained as crystalline precipitates and only the one having $\mathrm{SCH}_{3}$ as $\mathrm{R}_{1}$ and $\mathrm{R}_{2}$ substituents was successfully crystallized.

\section{Single crystal X-ray diffraction}

Crystals suitable for X-ray diffraction analysis were obtained from DMF solution by slow evaporation of the solvent. Details of data collection and structure refinement parameters for [ $\mathrm{PdSCH}_{3}$ ].2DMF are shown in Supporting Information (Table SI1). Compound $\left[\mathrm{PdSCH}_{3}\right] .2 \mathrm{DMF}$ crystallizes with $2 \mathrm{H}$-bonded DMF molecules in the asymmetric unit. Each Pd atom has a distorted square-planar $\mathrm{N}_{2} \mathrm{~S}_{2}$ coordination geometry provided by the doubly deprotonated tetradentate ligand $\mathrm{L}^{2-}$. Both $\mathrm{PdN}_{2} \mathrm{~S}_{2}$ fragments are essentially planar with $0.006 \AA$ distortion. However the overall complex is not flat as shown by 
the angle between the two phenyl of the methylsulfanylphenyl moieties equal to $27^{\circ}$. Selected bond lengths are provided in the caption of Figure 2.

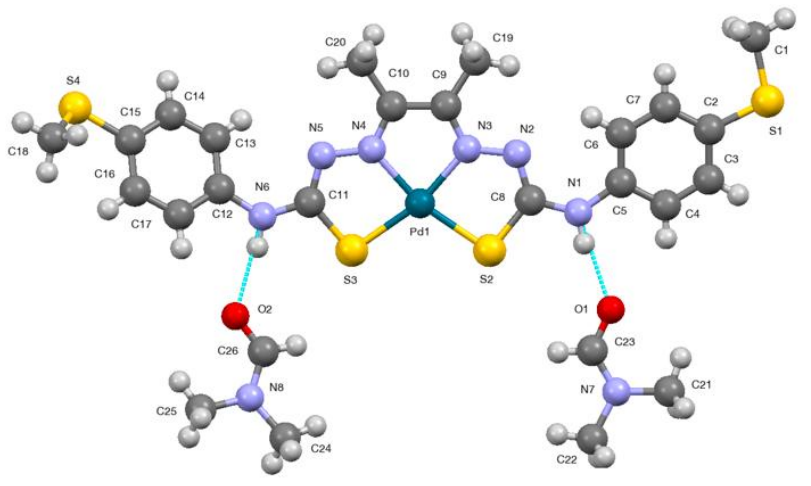

Fig.2 X-ray crystal structure of [PdSCH3].2 DMF with atom labelling scheme and ellipsoids parameters at $50 \%$ probability level. Selected bond lengths: Pd1-S Å. N2-C8 1.33(4) A, N3-C9 1.31(4) A, N4-N5 1.36(4) A, N4-C10 1.31(4) A, N5-C1 $1.33(4) \AA, C 9-C 191.49(4) \AA$, C10-C20 1.49(4) $\AA$. Hydrogen bonds parameters: N1

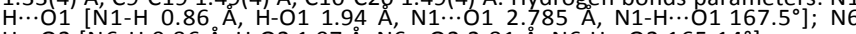

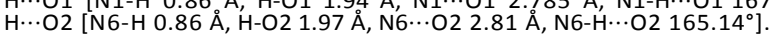

Comparison of $\mathbf{P d S C H}_{3}$ with its methoxy analogue ${ }^{24}$ shows that the two palladium complexes have similar structures. At first glance, the electronic properties of $R_{1}$ and $R_{2}$ substitutions do not seem to greatly influence the geometry of the complex. However, they may likely affect their electronic structures and their spectroscopic parameters.

\section{UV/Vis spectroscopy}

The optical properties of the ligands and the nickel complexes were followed by UV/Vis spectroscopy in DMF (Figures 3 and $\mathrm{SI}-1)$. The evolution of the spectra upon ligand metalation allowed us to confirm the nickel binding to the ligands for the whole series of systems.

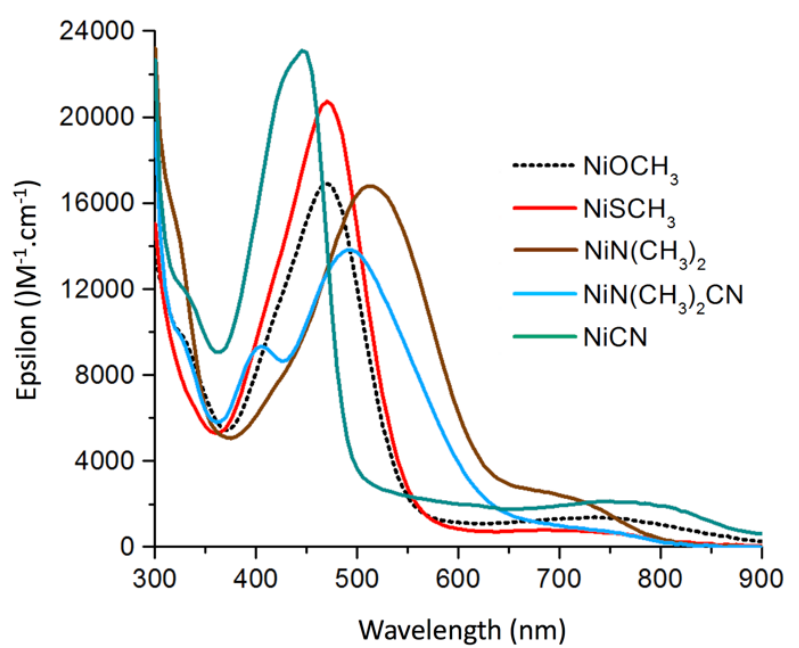

Fig.3 Electronic absorption spectra for the series of NiL complexes, concentration Fig.3 Electronic absorpt
of $0.05 \mathrm{mM}$ in DMF.
All ligands display one main absorption band centered at 350 $\mathrm{nm}$ while the NiL complexes display one main electronic transition in the 445-515 $\mathrm{nm}$ range and one shoulder around 700-750 nm (Table SI-2). The absorption band found at high energy has been previously attributed to a mixed metal-ligand to metal-ligand transition ${ }^{24}$ while the low-energy one is compatible with a d-d transition. The spectral features of the complex with the asymmetric ligand relate with the presence of different phenyl rings substituents. They are expected to affect individually the electron density distribution in the ligand upon excitation resulting in two high-energy absorption bands. Based on the spectral features reported in Figure 3 , it is worth noting that the different $R_{1}$ and $R_{2}$ substitutions have an electronic impact on the optical properties that influences the position of the main absorption band. Indeed, we observe a sequential bathochromic shift of the band when going from the $\mathrm{CN}$ substituent to the $\mathrm{N}(\mathrm{CH} 3)_{2}$ one which reflects the electron-donating abilities of the para substituents $\left(\mathrm{N}\left(\mathrm{CH}_{3}\right)_{2}\right.$ $>\mathrm{OCH}_{3}>\mathrm{SCH}_{3}>\mathrm{CN}$ ). This trend was further supported by TD-DFT calculations performed on the NiL series of complexes. Indeed, the predicted spectroscopic data provide calculated spectra that compare well with the experimental observations (Figure $\mathrm{SI}-17)$. Our computations adequately reproduce the energy of the key features of the experimental spectra, which highlight the electronic influence of the phenyl ring substituent on the optical properties of the systems.

\section{Electrochemical studies}

Cyclic voltammograms (CV) were recorded at room temperature at a glassy carbon electrode in Ar-deaerated anhydrous DMF containing $\mathrm{NBu}_{4} \mathrm{PF}_{6}$ as a supporting electrolyte. The redox behaviour of the ligands was investigated in the potential range between +0.5 and $-2.5 \mathrm{~V} v$. $\mathrm{Fc}^{+/ 0}$. We recorded the successive cyclic voltammograms of the $\mathbf{H}_{\mathbf{2}} \mathrm{L}$ ligands with and without $40 \mathrm{mM}$ of trifluoroacetic acid (Figure SI-4). In the absence of TFA, the CV show one irreversible wave in the cathodic region while in its presence, no catalytic wave was detected for the whole series. This is consistent to what was previously observed, confirming that the ligands themselves cannot perform catalytic proton reduction. $^{24}$

The CVs of the five NiL complexes recorded in anhydrous DMF under argon are shown in Figure 4. We can observe two quasireversible processes in the cathodic region from 0 to $-2.5 \mathrm{~V} v \mathrm{v}$. $\mathrm{Fc}^{+/ 0}$. The values of the processes in cathodic directions for the four NiL complexes are presented in Table 1 and compared with the $\mathrm{NiOCH}_{3}$ reference. The plot of the peak currents versus the square root of the scan rates for both cathodic and anodic waves were found to be linear, indicating that it is a diffusion-controlled process (Figure SI-5). A detailed analysis of the data presented in Figure 4 and Table 1 show that the $R_{1}$ and $R_{2}$ substitutions have an electronic effect influencing the redox properties of the NiL complexes. Indeed, the more positive is the $\sigma_{\text {para }}$ Hammett constant, the more positive is the potential for the first cathodic wave. These results thus 
support that the redox properties of the systems can be tuned by the ligand, highlighting the importance of the substituent at the para position of the phenyl ring.

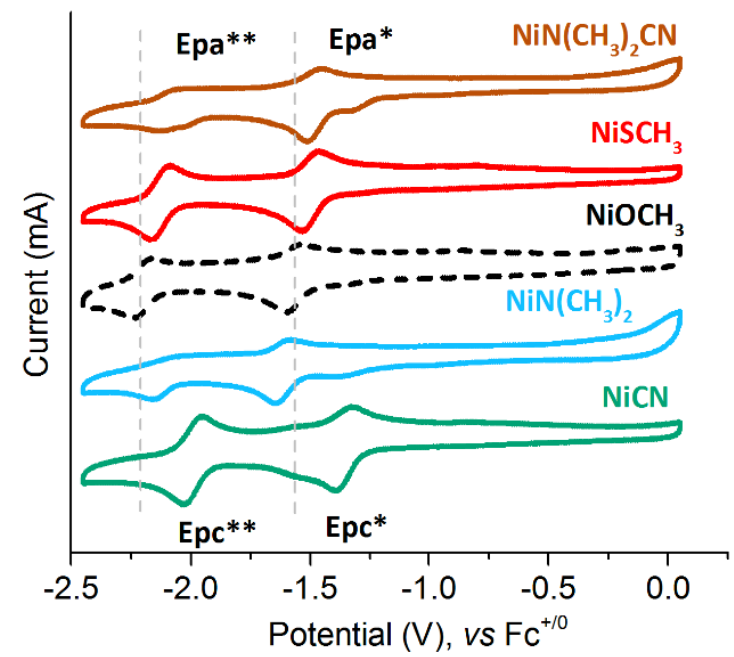

Fig.4 Cyclic voltammograms of the series of NiL complexes, concentration $1 \mathrm{mM}$ $\mathrm{mV} / \mathrm{s}$.

The trend observed for the first reduction process of the four NiL derivatives matches the relative electron-donating ability of the para-substituents. This is of interest as it provides qualitative information about the degree of electronic delocalization in the complex and gives insight into the radical distribution within the ligand framework. Indeed, our results show that electron withdrawing groups tend to diminish the potential required for reduction of the system which is likely due to stabilization of electron attachment energy and can be correlated to larger delocalization within the complex.

Table 1 Electrochemical data for NiL complexes. Potentials (V) refer to $\mathrm{Fc}^{+/ 0}$.

\begin{tabular}{c|c|c|c|c}
\multirow{2}{*}{ Complex } & \multirow{2}{*}{$\mathrm{Ni}^{\prime \prime} \mathrm{L} / \mathrm{Ni}^{\prime \prime} \mathrm{L}^{-}$} & \multirow{2}{*}{$\mathrm{Ni}^{\prime \prime} \mathrm{L}^{-} / \mathrm{Ni}^{\prime} \mathrm{L}^{2-}$} & \multicolumn{2}{|c}{$\Delta \mathrm{E}(\mathrm{V}) \mathrm{vs} . \mathbf{N i O C H}_{\mathbf{3}}$} \\
\cline { 4 - 5 } & -1.40 & -1.99 & -0.21 & -0.21 \\
\hline $\mathbf{N i C N}$ & -1.48 & -2.09 & -0.09 & -0.13 \\
\hline $\mathbf{N i N}\left(\mathrm{CH}_{3}\right)_{2} \mathbf{C N}$ & -1.57 & -2.20 & - & - \\
\hline $\mathrm{NiOCH}_{3}$ & -1.50 & -2.13 & -0.07 & -0.07 \\
\hline $\mathrm{NiSCH}_{3}$ & -1.62 & -2.11 & 0.04 & -0.08
\end{tabular}

\section{DFT calculations}

In previously published studies on thiosemicarbazone nickel complexes, ${ }^{24,32,34}$ DFT calculations were performed to understand their HER mechanism. The results offered important insight into the protonation sites of the complex, and also the electronic structure change upon reduction, the latter confirming the non-innocence of the ligand. In this work, we chose to focus solely on the two reduction processes, in order to infer the impact of the substituent on the electronic structures of the complexes (Figure SI-15). Our computational results confirm that the first reduction process remains ligandbased and show a fair agreement when comparing our calculated values with those from electrochemical measurements (Tables 2 and SI-5-9). Regarding the second reduction process, we assessed all spin electronic configurations for the doubly reduced species by considering the closed-shell singlet state $(S=0)$, the open-shell triplet state $(S=1)$ and the open-shell singlet state $(M s=0)$, the latter being evaluated using the Broken Symmetry (BS) approach. For all complexes, the open shell singlet $(\mathrm{Ms}=0)$ was found to be the lowest in energy and the predicted redox potentials compare well with experiment. Analysis of the Unrestricted Corresponding Orbitals confirm that the second reduction process is metal-centered (Figure $\mathrm{SI}-16$ ).

Table 2 Comparison of calculated and experimental shifts of redox potentials with respect to $\mathrm{NiOCH}_{3}$.

\begin{tabular}{c|c|c|c|c|c|c|c|c} 
& \multicolumn{8}{|c}{$\Delta \mathrm{E}(\mathrm{V})$ vs. $\mathbf{N i O C H}_{3}(\mathrm{BP} 86 / \mathrm{def} 2-\mathrm{TZVP})$} \\
\cline { 2 - 9 } & \multicolumn{2}{|c|}{$\mathrm{SCH}_{3}$} & \multicolumn{2}{c}{$\mathrm{N}\left(\mathrm{CH}_{3}\right)_{2}$} & \multicolumn{2}{c|}{$\mathrm{N}\left(\mathrm{CH}_{3}\right)_{2} \mathrm{CN}$} & \multicolumn{2}{c}{$\mathrm{CN}$} \\
\cline { 2 - 9 } & Calc. & Exp. & Calc. & Exp. & Calc. & Exp. & Calc. & Exp. \\
\hline $\mathrm{Ni}^{\prime \prime} \mathrm{L} / \mathrm{Ni}^{\prime \prime} \mathrm{L}^{-}$ & 0.02 & -0.07 & 0.11 & 0.04 & -0.11 & -0.09 & -0.33 & -0.26 \\
\hline $\mathrm{Ni}^{\prime \prime} \mathbf{L}^{-} / \mathrm{Ni}^{\prime} \mathbf{L}^{2-}$ & -0.08 & -0.07 & -0.03 & -0.09 & -0.20 & -0.12 & -0.31 & -0.21 \\
\hline
\end{tabular}

The qualitative trend for the different substituents and their relative order is well reproduced for both reduction steps. This serves as a validation of the choice of theoretical approach, in order to understand how substituents can modulate redox potentials.

When comparing the relative redox potentials (Figures SI20-23) with spin density distributions, we notice that less spin density in the $\mathrm{Ni}$ center yields less negative redox potentials, thus reducing the potential necessary for reduction. This is evidenced by the $\mathrm{CN}$ substituent, which seems to draw electronic density away from the metal center (Figure 5). Conversely, for $\mathrm{N}\left(\mathrm{CH}_{3}\right)_{2}$ we see the most negative redox potential, and it is the substituent that causes a subsequent localization of the spin density at $\mathrm{Ni}$ center. Thus, addition of electron-withdrawing groups tends to decrease the reduction potential, which will have interesting implications for catalysis as HER with our systems is supposedly initiated with the electrochemical step (electron transfer).




Fig.5: Localized SOMOs and spin density plots for the one-electron reduced species of the NiL series.

\section{Electrocatalytic proton reduction}

To examine the capability of the NiL complexes to mediate proton reduction catalysis, their electrochemical behaviour was studied by cyclic voltammetry in the presence of trifluoroacetic acid (TFA, $\mathrm{pK}_{\mathrm{a}}=6.00 \pm 0.3$ in DMF) ${ }^{38}$ as proton source. Cyclic voltammograms of the $\mathrm{NiL}$ complexes were recorded under argon in DMF solutions with increased concentrations of TFA and are shown in Figures 6, SI-6 and SI7.

Focusing on $\mathbf{N i S C H}_{3}$, the addition of $20 \mathrm{mM}$ of TFA triggers the appearance of two proton-dependent waves with peak potentials at -1.32 and $-2.18 \mathrm{~V}$ vs. $\mathrm{Fc}^{+/ 0}$, suggesting the existence of potential-dependent mechanisms (Figure SI-6). The current response of these peak-shaped waves is directly proportional to the concentration of protons in the electrolyte solution. While the peak potential of the more negative process is gradually shifted of from $-2.18 \mathrm{~V}$ to $-2.39 \mathrm{~V} \mathrm{vs}$. $\mathrm{Fc}^{+/ 0}$ (Figure SI-6), the first catalytic process potential remains mostly unaffected (Figure SI-7). Comparison with control experiments performed in the absence of $\mathbf{N i S C H}_{3}$ clearly indicates the role played by the nickel complex to in the observed current enhancement (Figure 6). As for $\mathbf{N i O C H}_{3}{ }^{[24]}$, we only investigated the process occurring at the more positive potentials with a midwave potential $=-1.32 \mathrm{~V}$.

To verify that the observed catalytic response in presence of TFA can be attributed to the complexes in solution and not due to adsorbed species on the surface electrode or degradation products, we performed a series of dip and rinse tests. After each electrochemical measurement, the working electrode was removed from the solution and immersed into a fresh DMF solution. $60 \mathrm{mM}$ TFA was then added and the electrochemical response was recorded between 0 to $-2.5 \mathrm{~V}$ vs. $\mathrm{Fc}^{+/ 0}$. For all complexes, only a residual background current was observed upon sweeping the potential in the cathodic region and upon addition of TFA, only the acid blank was observed (Figure SI-8). These control experiments confirm that no active adsorbed species is formed during electrocatalysis as no catalytic current could be detected indicating that the HER activity is due to dissolved NiL complexes. It is also worth mentioning that our systems displaying ligand-based reduction steps, it will limit the formation of $\mathrm{Ni}(0)$ species, preventing from a possible degradation pathway.

Table 3 HER parameters of the series of NiL complexes.

\begin{tabular}{c|c|c|c|c} 
Complex & $\begin{array}{c}\text { Hammett } \\
\text { constant }\end{array}$ & $\mathrm{Q}(\mathrm{C})$ & $\begin{array}{c}\text { Faradaic } \\
\text { efficiency } \\
\text { (FY, \%) }\end{array}$ & TON \\
\hline $\mathrm{NiSCH}_{3}$ & 0 & 61075 & 94 & 37 \\
$\mathrm{NiN}\left(\mathrm{CH}_{3}\right)_{2} \mathrm{CN}$ & $-0.83 / 0.66$ & 26169 & 86 & 14 \\
$\mathrm{NiN}\left(\mathrm{CH}_{3}\right)_{2}$ & -0.83 & 26065 & 56 & 10 \\
$\mathrm{NiCN}$ & 0.66 & 18617 & 63 & 8
\end{tabular}

To confirm that the observed catalytic waves correspond to the electrocatalytic reduction of protons into hydrogen, we performed bulk electrolysis experiments of DMF solutions of TFA (100 mM) and NiL (1 mM). Gas products were monitored by continuous in-line $\mathrm{GC}$ analysis. A potential of $-1.70 \mathrm{~V}$ versus $\mathrm{Fc}^{+/ 0}$ was applied to the mercury-pool working electrode resulting in the immediate formation of hydrogen. These experiments allow to rule out the possibility that proton reduction occurs as the result of deposition of nickel nanoparticles on the electrode surface since they would amalgamate within the mercury pool electrode. Consequently, inorganic coating cannot be responsible for catalysis with our NiL complexes and the catalysis is expected to be homogeneous in nature.

During the 16 hours electrolysis experiments, the four new NiL complexes were active in catalytic proton reduction. Their catalytic performances are summarized in Table 3 and graphically represented in Figure SI-9. It is worth mentioning that the maximum TON that can be obtained in our case is 50 . In similar condition, our reference catalyst $\left(\mathrm{NiOCH}_{3} \mathrm{Hammett}\right.$ constant $=-0.27$ ) mediated hydrogen evolution during a 16 hours electrolysis with $80 \%$ faradaic efficiency and a turnover number of 21 . These data confirm that $\mathbf{N i S C H}_{3}$ is more efficient to catalyze proton reduction when compared to the $\mathrm{NiOCH}_{3}$ complex which would support that chemical substitution of the ligand can help in enhancing the catalytic activity of our thiosemicarbazone nickel complexes. However, it is not possible at this stage to correlate the catalytic performances of the complexes with the electron-donating properties of their phenyl ring substituents even though we could observe a nice trend when looking at their redox and spectroscopic properties. 

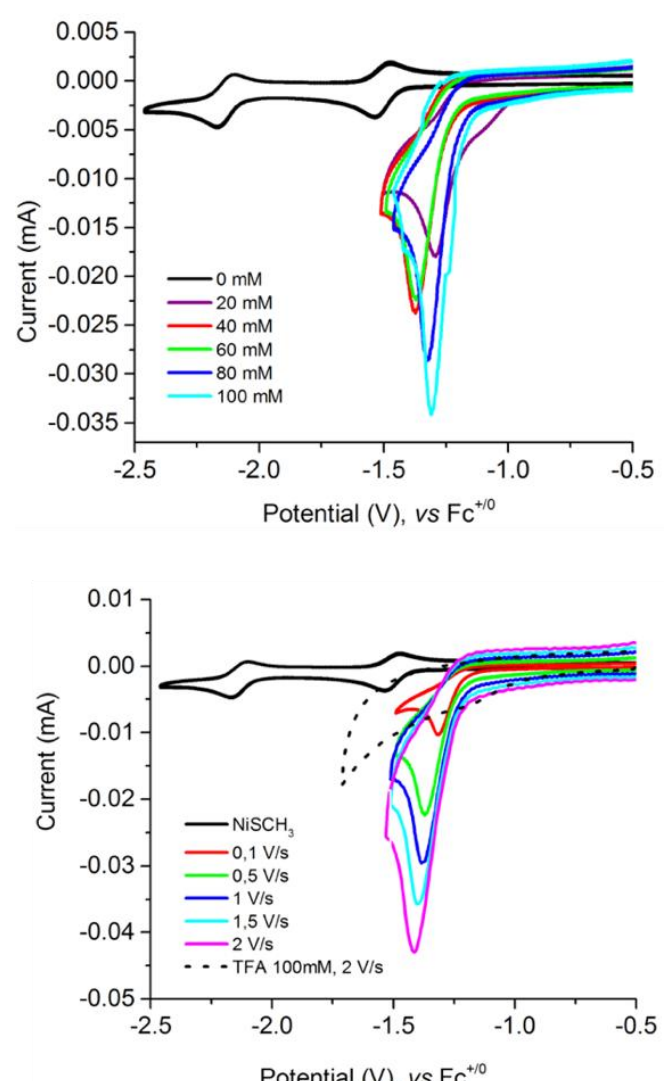

Fig.6 Successive cyclic voltammograms of a $1 \mathrm{mM}$ solution of $\mathrm{NiSCH}_{3}$ in DMF $(0.1$ TFA at $500 \mathrm{mV} / \mathrm{s}$ (top) and with $60 \mathrm{mM}$ TFA at five different scan rates (bottom).

\section{Mechanistic considerations and benchmarking of performances}

UV/Vis measurements performed in the absence and presence of trifluoroacetic acid (Figure SI-2) display almost identical features, indicating that the structure of $\mathbf{N i S C H}_{3}$ is unaffected by the addition of a proton source of such strength. Associated with the electrochemical behaviour of the complex in the presence of TFA, this suggests an ECEC mechanism (where E corresponds to an electron transfer step and $C$ to a chemical reaction, here a protonation) where a first reduction is required to trigger the initial protonation step. Such mechanism has been classically found for many $\mathrm{Ni}$ - and Cobased HER electrocatalysts. ${ }^{14,20,40-47}$

The foot-of-the-wave analysis (FOWA) was tentatively used in this work to estimate the relevant HER rate constants from CV measurements. ${ }^{31,47-49}$ Linearization of the catalytic wave was achieved by applying the equation corresponding to an ECEC mechanism with the second electron transfer being easier than the first one. The slope of the linear portion is expected to provide helpful kinetic information. ${ }^{49}$ From this point, the nature of the rate-determining step (RDS) must be examined. Considering fast and non-limiting electron transfers, kinetic limitations may arise either from the first $\left(k_{1}<<k_{2}\right)$ or the second $\left(k_{2}<<k_{1}\right)$ protonation step. In the present case, the mid-wave potentials of the series of complexes are less negative than the potential of the redox process triggering the catalytic wave, suggesting that $k_{2}$ is more likely the ratedetermining step. To confirm these findings, we estimated the maximum value of $k_{2}$ as approximately $k_{1} / 10^{50}$ to conform to a regime where catalysis is kinetically-controlled by the second protonation step. Under such condition, theoretical values of the catalytic enhancement ratio $i / i_{p}^{O}$ can be estimated in regard to the nature of the rate determining step. These estimates were made for the NiL series and are reported in Figures 7 and SI-11-13 at various scan rates.

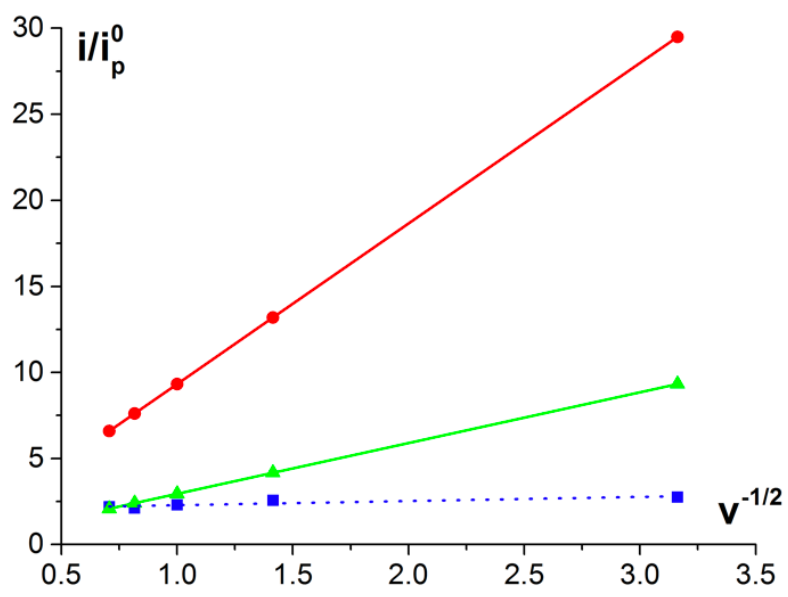

Fig.7 Theoretical values for $i_{c} / i_{p}^{0}$ for $\mathrm{NiSCH}_{3}$ in the presence of $60 \mathrm{mM}$ TFA and various scan rates plotted using equation (8). Red circles represent values were $k_{\text {cat }}=k_{1}=2812$
$281 \mathrm{M}^{-1} \mathrm{~s}^{-1}$.

Upon comparing the experimental data (blue squares) to the theoretical boundaries established for $k_{1}=k_{\text {cat }}$ (red circles) and $k_{2}=k_{\text {cat }}$ (green triangles), it is clearly observed that the experimental values for all complexes fall in the last region, precluding any insight regarding the nature of the rate determining step. Such situation thus prevents any unambiguous determination of the rate constant from FOWA (see Supporting Information).

To circumvent this limitation, the TOF values were determined from the bulk electrolyses experiments as previously reported. ${ }^{51,52}$ For heterolytic processes, the following equation was used:

$T O F=\frac{i_{e l}^{2}\left(1+\exp \left[\frac{F}{R T}\left(E_{a p p l}-E_{1 / 2}\right)\right]\right)}{F^{2} A^{2} D_{c a t}[\text { Cat }]^{2}}$

with $\mathrm{F}$ is Faraday's constant, A the surface area of the mercurypool working electrode, D the diffusion coefficient, [Cat] the concentration of the catalyst, $E_{\text {app } /}$ the applied potential during electrolyses, $E_{1 / 2}$ the midwave potential for the catalytic wave and $i_{e l}$ the current density during bulk electrolysis (see Supporting Information for the detailed analysis). The maximal turnover frequencies $\left(\mathrm{TOF}_{\max }\right.$ ) of the series of complexes were then evaluated using the following relation:

$T O F=\frac{T O F_{\max }}{1+\exp \left[\frac{F}{R T}\left(E_{a p p l}-E_{1 / 2}\right)\right]}$

TOF $_{\text {max }}$ values of $115.9,18.8,14.3$ and $10.2 \mathrm{~s}^{-1}$ were thus obtained for $\mathrm{NiSCH}_{3} ; \mathrm{NiN}\left(\mathrm{CH}_{3}\right)_{2} \mathbf{C N} ; \mathrm{NiN}\left(\mathrm{CH}_{3}\right)_{2}$ and $\mathrm{NiCN}$, respectively. For comparison, the $\mathrm{TOF}_{\max }$ value of the parent complex was also evaluated following the same procedure and a value of $89.7 \mathrm{~s}^{-1}$ was obtained for $\mathrm{NiOCH}_{3}$. Based on these 
values, the mid-wave potentials for each complex $(-1.32,-1.33$, $-1.31,-1.28$ and $-1.27 \mathrm{~V}$ vs. $\mathrm{Fc}^{+} / \mathrm{Fc}$ for $\mathbf{N i S C H}_{3} ; \mathbf{N i O C H}_{3}$ $\mathrm{NiN}\left(\mathrm{CH}_{3}\right)_{2} ; \mathrm{NiN}\left(\mathrm{CH}_{3}\right)_{2} \mathrm{CN}$ and $\mathrm{NiCN}$, respectively) and an apparent equilibrium potential of the $\mathrm{H}^{+} / \mathrm{H}_{2}$ couple $(-1.01 \mathrm{~V} v s$. $\mathrm{Fc}^{+} / \mathrm{Fc}^{24}$ ) at $1 \mathrm{M}$ TFA concentration, we could generate catalytic Tafel plots ${ }^{31}$ (Figures 8 and SI-14), connecting the turnover frequency (TOF) for the $\mathrm{H}_{2}$-evolution and the overpotential, $\eta$, an essential kinetic parameter for catalyst evaluation. ${ }^{39}$

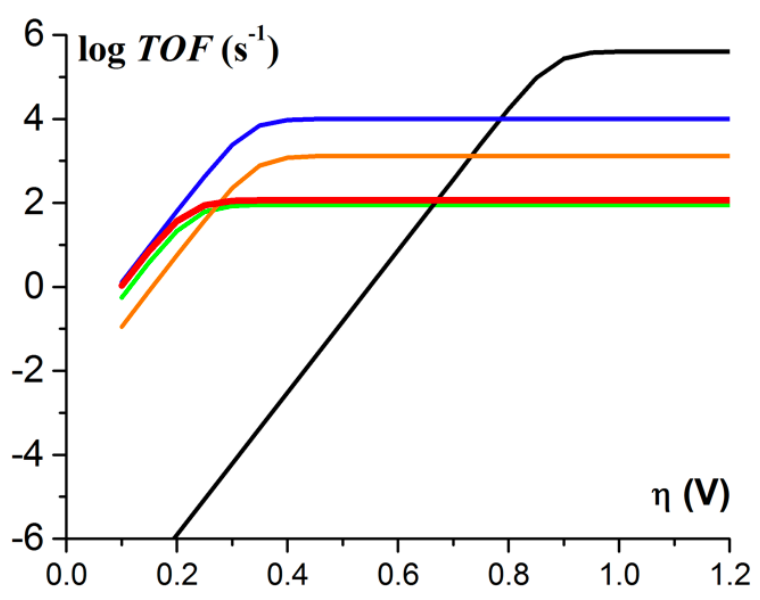

Fig.8 Catalytic Tafel plots: comparison of performances for $\mathrm{HER}$ catalyzed by $\mathrm{NiSCH}_{3}$ in DMF in the presence of $1 \mathrm{M}$ TFA (red line) and $\mathrm{NiOCH}_{3}{ }^{24}$ in DMF in the presence of $1 \mathrm{M}$ TFA (green line) with other catalysts reported in the literature. $\left[\mathrm{Ni}^{\prime}\left(\mathrm{P}_{2} \mathrm{PhN}_{2} \mathrm{C}_{6} \mathrm{H}_{4} \mathrm{X}\right)_{2}\right]^{2+}, \mathrm{X}=\mathrm{CH}_{2} \mathrm{P}(\mathrm{O})(\mathrm{OEt})_{2}, \mathrm{MeCN}, \mathrm{DMFH}^{\prime}$.

Focusing on $\mathbf{N i S C H}_{3}$ (red trace, Figure 7), we observe that this catalyst displays significant catalytic activity $(\log ($ TOF $)>1)$ for low overpotential values. It compares well with benchmark molecular catalysts like cobaloximes ${ }^{14}$ (blue trace, Figure 8 ) or nickel bisdiphosphine catalysts ${ }^{43,45,55}$ (orange trace, Figure 8) as far as the overpotential requirement is concerned. Interestingly, $\mathbf{N i S C H}_{3}$ features similar intrinsic catalytic performances when compared to $\mathrm{NiOCH}_{3}$. However, when looking at the macroscopic scale, the HER parameters (FY and TON) suggest that $\mathbf{N i S C H}_{3}$ displays an increased long-term stability with respect to the parent thiosemicarbazone complex. Taken together, these results support the fact that thiomethyl substitution on the ligand influences the electronic and redox properties of the system which directly impact its catalytic behavior. However, it seems unclear whether there is an actual relationship between the catalytic observables and the electronic properties of the phenyl ring substituent within the NiL series of complexes. While the overpotential of the four derivatives increases when going from the $\mathrm{CN}$ substituent to the $\mathrm{N}(\mathrm{CH} 3)_{2}$ one and matches the relative electron-donating ability of the para-substituents, the TOF $_{\max }$ values seem to go in the opposite direction with smaller values being obtained for the more electron-withdrawing substituents (Figure SI-14).

\section{Conclusions}

We have reported a new series of thiosemicarbazone nickel complexes for which the $R_{1}$ and $R_{2}$ phenyl ring substituents were chosen to cover a wide range of electron-donating properties. This approach was meant to modulate the electronic properties of the catalysts based on the different Hammett Sigma Constants at the para position of the benzene. The complexes were experimentally and theoretically characterized, and shown to exhibit from moderate to high electrocatalytic activity for proton reduction to dihydrogen. Detailed analysis of the electrocatalytic data allowed to benchmark the performances of the series of complexes and catalytic Tafel plots showed that $\mathbf{N i S C H}_{3}$ compares well with benchmark molecular catalysts as far as the overpotential requirement is concerned. Our results indicate that the chemical nature of the substituent in the para position of the ligand indeed influences the electrochemical and catalytic behaviour of the system. Further work will be necessary to decipher the actual relationship between the electrondonating ability of the phenyl ring substituent of the complexes and the HER parameters as opposite trends were obtained when looking at the overpotential and the TOF max values. This encourages us to pursue our research on improving the catalytic performances of our nickel thiosemicarbazone complexes and on unravelling the key elements that both affect and control the redox and electronic properties of these HER catalysts. ${ }^{34,56,57}$

\section{Experimental Section}

All solvents were purchased from Sigma Aldrich and used without further purification, and for reagents chemical were purchased from Alfa Aesar for isothiocyanate derivative. Syntheses of isothiocyanate derivative were performed according to procedures described by Demchenko et al..$^{58}$ and Lakshmi et al. ${ }^{59}{ }^{1} \mathrm{H}$ NMR spectra were recorded on Bruker 400 and $300 \mathrm{MHz}$ Avance III nanobay. Chemical shifts for ${ }^{1} \mathrm{H}$ NMR spectra refer to TMS or the residual protonated solvent. IR spectra were recorded with Bruker TENSOR27 spectrometer equipped with a single-reflection DuraSamplIR diamond. ESIMS analyses were performed using a SYNAPT G2 HDMS (Waters) spectrometer equipped with a pneumatically assisted Atmospheric Pressure Ionization (API) source. Samples were ionized by positive electrospray mode as follows: ion-spray voltage: $2.8 \mathrm{kV}$; sampling cone: $20 \mathrm{~V}$ for $\mathbf{N i S C H}_{3}, \mathbf{N i C N}$, $\mathrm{NiN}\left(\mathrm{CH}_{3}\right)_{2}$ and $40 \mathrm{~V}$ for $\mathrm{NiN}\left(\mathrm{CH}_{3}\right)_{2} \mathrm{CN}$; nitrogen flux (nebulization): $100 \mathrm{~L} \mathrm{~h}^{-1}$. High resolution mass spectra (HRMS) were performed on a QStar Elite (Applied Biosystems SCIEX) spectrometer equipped with atmospheric pression ionization source (API) pneumatically assisted. The samples were placed in a methanol/3 $\mathrm{mM}$ ammonium acetate. The results were validated by three measurements. UV/Vis spectra were recorded on a Varian Cary 50 spectrophotometer.

\section{Single crystal X-ray diffraction}

A suitable crystal for compound [PdSCH3].2DMF was measured on a Rigaku Oxford Diffraction SuperNova diffractometer at room temperature at the CuK $\alpha$ radiation $(\lambda=1.54184 \AA)$. Data collection reduction and multiscan ABSPACK correction were performed with CrysAlisPro (Rigaku 
Oxford Diffraction). Using Olex2 $2^{60}$ the structures were solved by direct methods with SHELXT ${ }^{61}$ and SHELXL ${ }^{62}$ was used for full matrix least squares refinement. All $\mathrm{H}$-atoms were found experimentally except those for the methyl groups that were introduced at geometrical positions. Their coordinates and Uiso parameters were constraint to $1.5 \mathrm{Ueq}$ (parent atoms) for the methyl groups and to 1.2Ueq (parent atom) for the other carbons and the amines. The crystallographic and refinement parameters are given in supporting information. CCDC number 1971128 contains the supplementary crystallographic data for this paper.

\section{Electrochemistry}

Cyclic voltammetry experiments were performed using a BioLogic SP300 potentiostat and a three-electrode set-up consisting of a glassy carbon working electrode, a platinum wire counter electrode and a Leakless $(\mathrm{Ag} / \mathrm{AgCl})$ reference electrode. Ferrocene was used as an internal standard with $\mathrm{E}^{0}\left(\mathrm{Fc}^{+} / \mathrm{Fc}\right)=0.52 \mathrm{~V}$ vs. $\mathrm{Ag} / \mathrm{AgCl}$ for each measurement. All studies were performed in deoxygenated DMF containing $\mathrm{NBu}_{4} \mathrm{PF}_{6}(0.1 \mathrm{M})$ as supporting electrolyte. Controlled potential electrolysis experiments were carried out in two-compartment cell. The volume of solution (DMF, $0.1 \mathrm{M} \mathrm{NBu}_{4} \mathrm{PF}_{6}$ ) used in the working compartment of the cell was $2 \mathrm{ml}$. Controlled potential electrolysis experiments were carried out in twocompartment cell. The volume of solution (DMF, $0.1 \mathrm{M}$ $\mathrm{NBu}_{4} \mathrm{PF}_{6}$ ) used in the working compartment of the cell was 8 $\mathrm{ml}$. The working electrode used was a pool of mercury, separated from the coiled platinum wire counter electrode by a porous frit. Bulk electrolysis solutions were purged witch $\mathrm{N}_{2}$ gas for at least $20 \mathrm{~min}$ prior to electrolysis and stirred throughout bulk electrolysis experiment. During the experiment, the cell was continuously purged with nitrogen (5 $\mathrm{mL} \cdot \mathrm{min}^{-1}$ ) and the output gas was analyzed at two-minute intervals in a Perkin Elmer Clarus 500 gas chromatographer using a previously described setup

\section{DFT calculations}

All theoretical calculations used ORCA 4.1.2. ${ }^{63,64}$ Geometry optimizations and numerical frequency calculations were performed for all intermediates using B3LYP and BP86, with def2-TZVP as the basis set. ${ }^{65-72}$ We chose to use 'Grid4' and 'TightSCF' for integration and convergence criteria, following ORCA notation, and CPCM as the implicit solvation model for the solvent effect of DMF. ${ }^{69}$ Single-point Broken-Symmetry DFT calculations were performed to evaluate all possible spin configurations using the "FlipSpin" feature of ORCA. ${ }^{72,73}$ Free energy differences for the redox potential calculations were extracted from the Gibbs free energies obtained from numerical frequencies calculations. Since experimental values are reported with respect to the ferrocene electrode in DMF, we need to shift our calculated absolute potentials. We calculated the Gibbs free energy difference for the ferrocene reduction in DMF, obtaining $\triangle \mathrm{G}(\mathrm{BP} 86)=4.87 \mathrm{eV}$ and $\Delta G(B 3 L Y P)=4.36 \mathrm{eV}$. While those values differ by $0.5 \mathrm{eV}$, they inherit the behaviours of each functional, thus offering the possibility of cancelling systematic errors. Optical properties were predicted from additional single-point calculations using the CAM-B3LYP functional ${ }^{74,75}$ and the def2-TZVP basis set. Electronic transition energies and dipole moments for all models were calculated using time-dependent DFT (TD-DFT) ${ }^{76-}$ 78 within the Tamm-Dancoff approximation. ${ }^{79,80}$ To increase computational efficiency, the RI approximation ${ }^{80}$ was used in calculating the Coulomb term and at least 40 excited states were calculated in each case. All chemical structure images were generated using Chemcraft. ${ }^{82}$

\section{Conflicts of interest}

There are no conflicts to declare

\section{Author contributions}

M.P. and A.P. carried out the experimental work under the supervision of M.O. T.S. and N.Q. contributed to the analysis of the electrochemical data. A.B. carried out the theoretical calculations. J.F performed the measurements of gas production and M.G. performed X-ray analysis. J.M., R.H. and M.O. analysed and interpreted the experimental data. M.R. and M.O. conceived and designed the project. M.O prepared the manuscript. All authors reviewed and contributed to the manuscript.

\section{Acknowledgements}

The authors gratefully acknowledge research support of this work by the French National Research Agency (ANR JCJC, CODEC, ANR19-CE05_0030_01 and Labex program, ARCANE, ANR-11-LABX0003-01, Graduate school of Chemistry, Biology and Health of Univ. Grenoble Alpes, CBH-EUR-GS, ANR-17-EURE-0003).

\section{Notes and references}

1 D. A. King, Science, 2004, 303, 176.

2 J. A. Turner, Science, 2004, 305, 972.

3 P. P. Edwards, V. L. Kuznetsov, W. I. F. David, N. P. Brandon, Energy Policy, 2008, 36, 4356.

4 J. R. McKone, S. C. Marinescu, B. S. Brunschwig, J. R. Winkler, H. B. Gray, Chem. Sci. 2014, 5, 865.

5 Special issue on "Hydrogenases", Eur. J. Inorg. Chem., 2011, 915.

6 W. Lubitz, H. Ogata, O. Rüdiger, E. Reijerse, Chem. Rev., 2014, 114, 4081.

7 T. R. Simmons, G. Berggren, M. Bacchi, M. Fontecave, V. Artero, Coord. Chem. Rev., 2014, 270 -271, 127.

8 T. B. Rauchfuss, Acc. Chem. Res., 2015, 48, 2107.

9 M. Y. Darensbourg, E.J. Lyon, J.J. Smee, Coord. Chem. Rev., 2000, 206, 533.

10 Z. Li, Y. Ohki, K. Tatsumi, J. Am. Chem. Soc., 2005, 127, 8950.

11 D. Brazzolotto, M. Gennari, N. Queyriaux, T.R. Simmons, J. Pecaut, S. Demeshko, F. Meyer, M. Orio, V.Artero, C. Duboc, Nat. Chem., 2016, 8, 1054. 
12 S. Canaguier, M. Field, Y. Oudart, J. Pécaut, M. Fontecave, V. Artero, Chem. Comm., 2010, 46, 5876.

13 M. L. Helm, M. P. Stewart, R. M. Bullock, M. Rakowski DuBois, D. L. DuBois, Science, 2011, 333, 863.

14 M. Razavet, V. Artero, M. Fontecave, Inorg. Chem., 2005, 44, 4786.

15 P. Zhang, M. Wang, Y. Yang, T. Yao, L. Sun, Angew. Chem., 2014, 53, 13803

16 S. Cherdo, S. El Ghachtouli, M. Sircoglou, F. Brisset, M. Orio, A. Aukauloo, 2014, Chem. Comm., 2014, 50, 13514.

17 E. J. Thompson, L. A. Berben, Angew. Chem., 2015, 54, 11642.

18 M. Beyler, S. Ezzaher, M. Karnahl, M.-P. Santoni, R. Lomoth, S. Ott, Chem. Commun., 2011, 47, 11662.

19 E. H. Karunadasa, C. J. Chang, J. R. Long et al, Nature, 2010, 464, 1329.

20 J. L. Dempsey, B. S. Brunschwig, J. R. Winkler, H. B. Gray, Acc. Chem. Res., 2009, 42, 1995.

21 X. Jing, P. Wu, X. Liu, L. Yang, C. He, C. Duan, New J. Chem.,2015, 39, 1051.

22 W. R. McNamara et al, Dalton Trans., 2015, 44, 14265

23 A. Z. Haddad, B. D. Garabato, P. M. Kozlowski, R. M. Buchanan C.A. Grapperhaus, J. Am. Chem. Soc., 2016, 138 7844.

24 T. Straistari, J. Fize, S. Shova, M. Réglier, V.Artero, M. Orio, Chem. Cat. Chem., 2017, 9, 2262.

25 A. Z. Haddad, S. P. Cronin, M. S. Mashuta, R. M. Buchanan, C. A. Grapperhaus, Inorg. Chem., 2017, 56, 11254.

26 T. Straistari, R. Hardré, J. Fize, S. Shova, M. Réglier, V. Artero, M. Orio, Chem. Eur. J., 2018, 24, 8779.

27 W. R. McNamara, Z. Han, C.-J. Yin, W. W. Brennessel, P. L. Holland, R. Eisenberg, Proc. Natl. Acad. Sci. U.S.A., 2012, 109,15594 .

28 W. R. McNamara, Z. Han, P. J. Alperin, W. W. Brennessel, P. L. Holland, R. Eisenberg, J. Am. Chem. Soc., 2011, 133, 15368.

29 N. Queyriaux, D. Sun, J. Fize, J. Pecaut, M. J. Field, M. Chavarot-Kerlidou, V. Artero, J. Am. Chem. Soc., DOI: 10.1021/jacs.9b10407.

30 B. H. Solis, S. Hammes-Schiffer, Inorg. Chem., 2014, 53, 6427.

31 V. Artero, J.-M. Saveant, Energy Environ. Sci., 2014, 7, 3808.

32 R. Jain, A. A. Mamun, R. M. Buchanan, P. M. Kozlowski, C. A. Grapperhaus, Inorg. Chem. 2018, 57, 13486.

33 S. Panagiotakis, G. Landrou, V. Nikolaou, A. Putri, R. Hardré J. Massin, G. Charalambidis, A. G. Coutsolelos, M. Orio, Front. Chem., 2019, 7, 405.

34 A. Barrozo, M. Orio, Chem. Sus. Chem., 2019, 12, 4905.

35 R. C. Kerber, J.Chem. Educ., 2006, 83, 223.

36 L. M. Stock, J. Chem. Educ., 1972, 49, 400.

37 T. Straistari, R. Hardré, J. Massin, M. Attolini, B. Faure, M. Giorgi, M. Réglier, M. Orio, Eur. J. Inor. Chem., 2018, 2259.

38 V. Fourmond, S. Canaguier, B. Golly, M.J. Field, M. Fontecave, V. Artero, Energy Environ. Sci., 2011, 4, 2417.

39 V. Fourmond, P.A. Jacques, M. Fontecave, V. Artero, Inorg. Chem., 2010, 49, 10338.

40 J. L. Dempsey, B. S. Brunschwig, J. R. Winkler, H. B. Gray, Acc. Chem. Res., 2009, 42, 1995.

41 J. L. Dempsey, J. R. Winkler, H. B. Gray, J. Am. Chem. Soc., 2010, 132, 16774 .

42 N. Kaeffer, M. Chavarot-Kerlidou, V. Artero, Acc. Chem. Res. 2015, 48, 1286.

43 A. D. Wilson, R. H. Newell, M. J. McNevin, J. T. Muckerman, M. R. DuBois, D. L. DuBois, J. Am. Chem. Soc., 2006, 128, 358

44 E. S. Wiedner, A. M. Appel, D. L. DuBois, R. M. Bullock, Inorg. Chem., 2013, 52, 14391.

45 E. S. Wiedner, J. A. S. Roberts, W. G. Dougherty, W. S. Kassel, D. L. DuBois, R. M. Bullock, Inorg. Chem., 2013, 52, 9975.
46 N. Queyriaux, R.T. Jane, J. Massin, V. Artero, M. ChavarotKerlidou, Coord. Chem. Rev., 2015, 304-305, 3.

47 E. S. Rountree, B. D. McCarthy, T. T. Eisenhart, J. L. Dempsey, Inorg. Chem., 2014, 53, 9983

48 C. Costentin, M. Drouet, M. Robert, J.-M. Saveant, J. Am. Chem. Soc., 2012, 134, 1123.

49 C. Costentin, J.-M. Saveant, ChemElectroChem, 2014, 1 , 1226

50 N. Elgrishi, M. B. Chambers, M. Fontecave, Chem. Sci., 2015 6, 2522.

51 S. Roy, B. Sharma, J. Pećaut, P. Simon, M. Fontecave, P. D. Tran, E. Derat, V. Artero, J. Am. Chem. Soc., 2017, 139, 3685.6

52 N. Queyriaux, D. Sun, J. Fize, J. Pecaut, M. J. Field, M. Chavarot-Kerlidou, V. Artero, J. Am. Chem. Soc., 2020, 142 274.

53 I. Bhugun, D. Lexa, J.-M. Saveant, J. Am. Chem. Soc., 1996, 118, 3982

54 N. Coutard, N. Kaeffer, V. Artero; Chem. Commun., 2016, 52, 13728.

55 U. J. Kilgore, J. A. S. Roberts, D. H. Pool, A. M. Appel, M. P. Stewart, M. R. DuBois, W. G. Dougherty, W. S. Kassel, R. M. Bullock, D. L. DuBois, J. Am. Chem. Soc., 2011, 133, 5861.

56 S. P. Cronin, A. Al Mamun, M. J. Toda, M. S. Mashuta, Y. Losovyj, P.M. Kozlowski, R. M. Buchanan, C. A. Grapperhaus, Inorg. Chem. 2019, 58, 19, 12986.

57 C. A. Calvary, O. Hietsoi, J. M. Strain, M. S. Mashuta, J. M. Spurgeon, R. M.; Buchanan, C. A. Grapperhaus, Eur. J. Inorg. Chem. 2019, 3782

58 A. M. Demchenko, V. A. Yanchenko, V. V. Kisly, M.S. Lozinskii, Chem. Heterocycl. Compd., 2005, 41,668.

59 B. Lakshmi, P. G. Avaji, K. N. Shivananda, P. Nagella, S. H. Manohar, K.N . Mahendra, Polyhedron, 2011, 30,1507.

60 O. V. Dolomanov, L. J. Bourhis, R. J. Gildea, J. A. K. Howard, H. J. Puschmann, Appl. Cryst., 2009, 42, 339.

61 G. M. Sheldrick, Acta Cryst., 2015, A71, 3

62 G. M. Sheldrick, Acta Cryst., 2015, C71, 3.

63 F. Neese, Wiley Interdiscip. Rev. Comput. Mol. Sci., 2012, 2 73.

64 F. Neese, Wiley Interdiscip. Rev. Comput. Mol. Sci., 2018, 8 e1327.

65 A. D. Becke, J. Chem. Phys., 1993, 98, 5648

66 C. Lee, W. Yang, R. G. Parr, Phys. Rev. B, 1988, 37, 785

67 J. P. Perdew, Phys. Rev. B, 1986, 33, 8822

68 J. P. Perdew, Phys. Rev. B, 1986, 34, 7406

69 A. D. Becke, Phys. Rev. A, 1988, 38, 3098.

70 A. Schaefer, C. Huber, R. Ahlrichs, J. Chem. Phys., 1994, 100, 5829.

71 V. Barone, M. Cossi, J. Phys. Chem. A, 1998, 102, 1995.

72 L. Noodleman, J. Chem. Phys., 1981, 74, 5737-5743

73 L. Noodleman, E. R. Davidson, Chem. Phys., 1986, 109, 131 143.

74 T. Yanai, D. P. Tew, N. C. Handy, Chem. Phys. Lett., 2004, 393 51.

75 Y. Tawada, T. Tsuneda, S. Yanagisawa, T. Yanai, K. Hirao, J. Chem. Phys., 2004, 120, 8425.

76 M. E. Casida, In Recent Advances in Density Functional Methods, Chong, D.P. Ed. World Scientific: Singapore, 1995.

77 R. E. Stratmann, G. E. Scuseria, M. J.Frisch, J. Chem. Phys. $1998,109,8218$

78 R. Bauernschmitt, R. Ahlrichs, Chem. Phys. Lett., 1996, 454 464.

79 S. Hirata, M. Head-Gordon, Chem. Phys. Lett., 1999, 314, 291.

80 S. Hirata, M. Head-Gordon, Chem. Phys. Lett., 1999, 302 375.

81 F. Neese, J. Chem. Phys. 2001, 115, 11080 
82 "Chemcraft - Graphical software for visualization of quantum chemistry computations.", https://www.chemcraftprog.com. 